\title{
Sporadic flowering of Bambusa mizorameana Naithani in Mizoram
}

\author{
David C. Vanlalfakawma, ${ }^{1 *}$ Sukanta Kumar Sen, ${ }^{1}$ S.K. Tripathi, ${ }^{2}$ F. Lalnunmawia ${ }^{3}$ \\ 1Department of Botany, Visva Bharati University, Santiniketan 731236, West Bengal, India \\ ${ }^{2}$ Department of Forestry, ${ }^{3}$ Department of Botany, Mizoram University, Tanhril 796004, Mizoram, India
}

\begin{abstract}
Mizoram, one of the states in northeast India, is known for its rich bamboo resources. Mizoram has been unceasingly experiencing flowering of bamboo. Recently, a new species of bamboo, Bambusa mizorameana, was described from Mizoram. It is a less common species, and its distributions within the state are also very limited. Specimens were also collected from Manipur. There has been no previous report of its inflorescence. The sporadic flowering of the species in certain areas within the nearby forest of Aizawl city, observed since 2017 are reported in this paper.
\end{abstract}

Received 14 January 2018 Accepted 21 March 2019

*For correspondence: Vanlalfakawma cfakawma@gmail.com

Contact us: sciencevision@outlook.com

Keywords: Bamboo, Bambusa mizorameana, bamboo flowering, Mizoram.

Since the past ten years, Mizoram has been continuously experiencing flowering of bamboo. The gregarious flowering of Mellocana baccifera during 2006-2009 ${ }^{1}$ was the most devastated one. Since 2011, sporadic flowering of Dendrocalamus longispathus has been continuing till date. ${ }^{2}$ Sporadic flowering of Bambusa tulda was also observed in the western belt of the state in 2015 , which was confined only in those areas. $^{3}$

Bambusa mizorameana Naithani, ta-lan in Mizo, a less congested bamboo is a recently described species from Mizoram, India. ${ }^{4}$ It is reported to be endemic to Mizoram and Manipur. ${ }^{5}$ It is vernacularly named as 'Talan'4 and 'Khokwa' ${ }^{6}$ in Mizoram and Manipur respectively. Apart from the evaluation of the anatomical and physical properties of three years old culms of $B$. mizorameana Naithani reported from Manipur ${ }^{6}$, not much scientific studies have been conducted about it, till date. The inflorescence of this species has also not been reported, till date. ${ }^{6}$

It is one of the less common bamboo species in Mizoram. Its distribution in the state is mostly confined to the slopes of lower hills. Its uses are also limited mostly to constructional purposes, mainly for purlin in traditional houses and jhum huts. However, in Manipur, it is also used as baskets and handles for agriculture implements. $^{5}$

Flowering of $B$. mizorameana Naithani was first observed in January 2017 at home gardens around Zemabawk, Aizawl (Figure 1). Survey was conducted throughout the year at the natural growing site of the species. So far, flowering was observed in three natural growing sites at Zemabawk, a locality in the North-Eastern part of the Aizawl City. The inflorescence of $B$. mizorameana Naithani was observed in and around Zemabawk at $23^{\circ} 44^{\prime} 10.90 \mathrm{~N}$ latitude and $91^{\circ} 46^{\prime} 08.45 \mathrm{E}$ longitude (Figure 2). The flowering clumps/specimen was compared with the clumps from the original locality (from where it was described) at Khawruhlian. After careful comparison of the morphological identification keys as described by Naithani ${ }^{4}$, the two specimens were found to be closely matching with each other in all aspects.

\section{Acknowledgement}

Senior author greatly acknowledged the research fellowship granted by the Science \& Engineering 

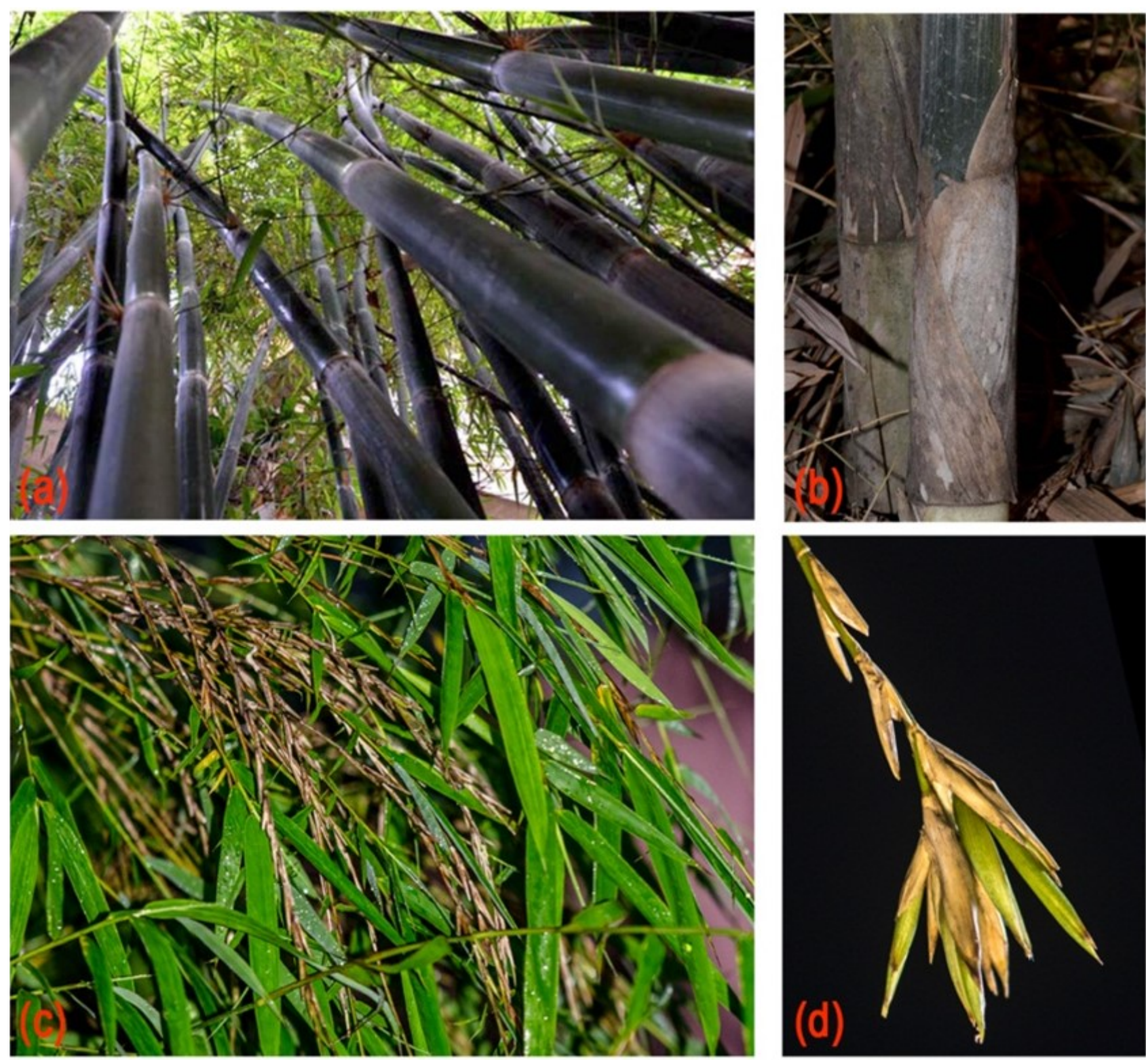

Figure 1 | Inflorescence in Bambusa mizorameana Naithani. (a) Clumps. (b) Culm sheath. (c) Initial stage. (d) Close-up of initial stage. 

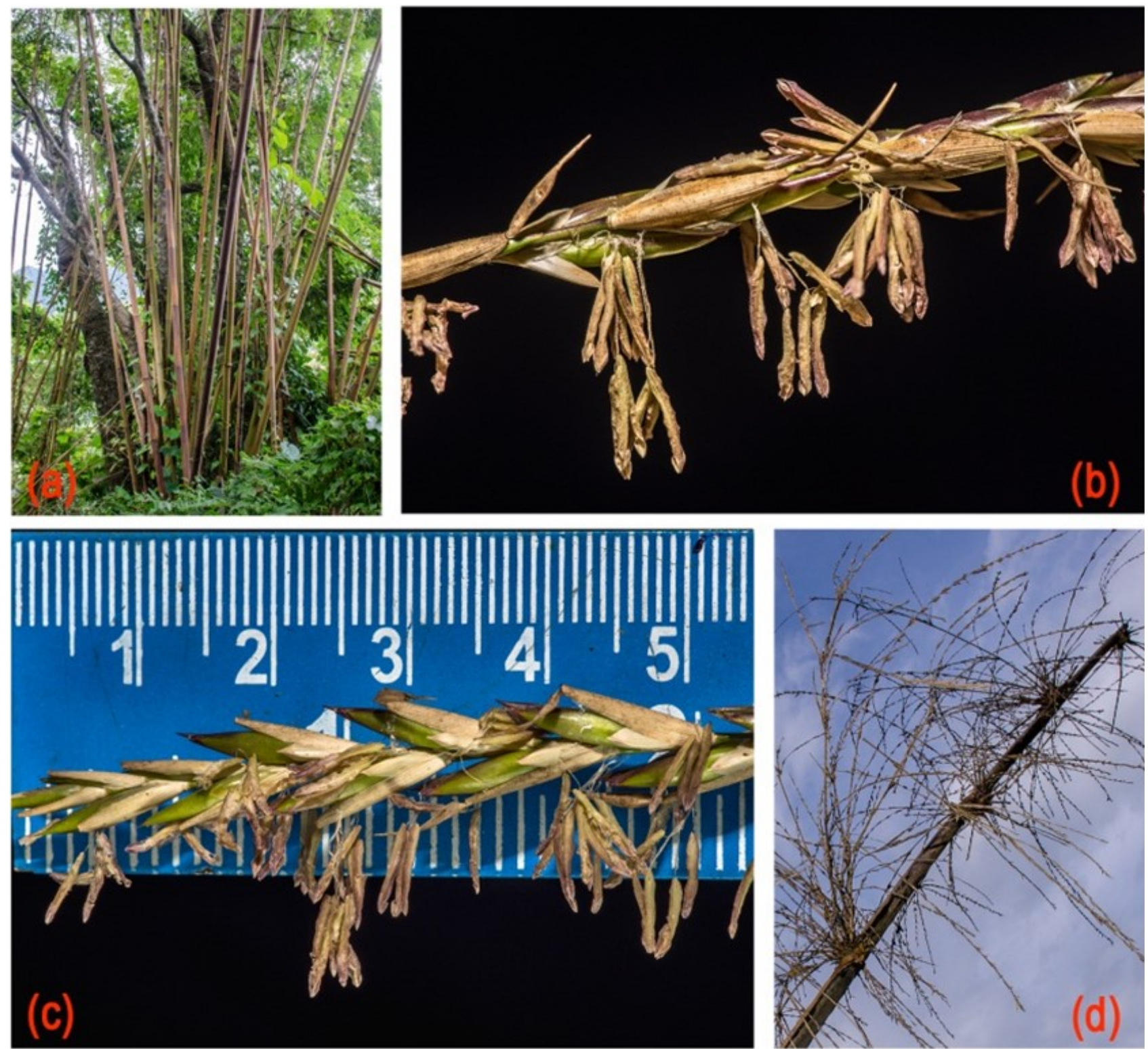

Figure 2 | Inflorescence in Bambusa mizorameana Naithani. (a) Clumps of flowwering bamboo. (b) A dehisce inflorescence. (c) scaling in $\mathrm{mm}$. (d) Culm. 
Research Board (SERB) Government of India (PDF/2016/00123) in the form of National PostDoctoral Fellowship.

\section{References}

1. Jeeva, S., Kiruba, S., Lalhruaitluanga, H., Prasad, M.N.V. \& Rao, R.R. (2009) Flowering of Melocanna baccifera (Bambusaceae) in northeastern India. Current Science, 96(9), 1165-1166.

2. Sharma, H.R., Yadav, S., Deka, B., Meena, R.K. \& Bisht, N.S. (2014). Sporadic flowering of Dendrocalamus longispathus (Kurz) Kurz in Mizoram, India. Tropical Plant Research, 1(1), 26-27.
3. Vanlalfakawma, D.C., Lalnunmawia, F., Tripathi, S.K. \& Sen, S.K. (2017). Sporadic flowering of Bambusa tulda in Mizoram: A preliminary report. Science Vision, 17(3), 160-162.

4. Naithani, H. B. (2009). Bambusa mizorameana. A new species of bamboo from Mizoram, India. Indian Forester, 135(9), 1291-1292.

5. Anon. (2010). Bamboos of Mizoram. Environment and Forest Department, Government of Mizoram, p. 63.

6. Kumar, Y.B., Sharma, M. \& Sharma, C.L. (2017). Anatomical and physical properties of Bambusa mizorameana Naithani. International Journal of Advanced Research 3(4), 479-486. 